\title{
Preparation of Nano Titanium Dioxide Using the Sol-Gel Method to Use in Friendly Environment Coatings
}

\author{
${ }^{1}$ Abeer Abd Saleh*, ${ }^{2}$ Quraish Abbas, ${ }^{3}$ Seenaa Ibraheim, ${ }^{4}$ Ibrahim Muhammed, ${ }^{1}$ Mayes Sameer Hameed, \\ ${ }^{1}$ Rukiya Abd Alsahb Lafta, ${ }^{1}$ Sarah Gameel Dawood, ${ }^{3}$ Ban Mazan \\ ${ }^{1}$ National Center for Packing and Packaging/ Corporation of Research and Industrial Development - Iraq \\ ${ }^{2}$ Chemical and Petrochemical Research Center/ Corporation of Research and Industrial Development - Iraq \\ ${ }^{3}$ Department of Physics, College of Science, University of Baghdad - Iraq \\ ${ }^{4}$ State Company for Mining Industries, Ministry of Industry and Minerals - Iraq
}

\section{Article information}

\section{Article history:}

Received: July, 30, 2021

Accepted: August, 20, 2021

Available online: October, 20, 2021

Keywords:

Local paint,

Sol-gel,

$\mathrm{TiO}_{2}$

*Corresponding Author:

Abeer Abd Saleh

zoozaphysics3@gmail.com

DOI:

https://doi.org/10.53523/ijoirVol8I2ID60

\begin{abstract}
In this research, preparation of titanium dioxide nanomaterial $\left(\mathrm{TiO}_{2}\right)$ using sol-gel method was achieved. $2.5 \mathrm{~g}$ weight of the titanium dioxide nanoparticles were added to the local paint using the casting method. Thin films were prepared by drop casting the paint onto the surface of pre-prepared samples, then several tests were carried out including adhesion test, hardness test (Shore B), brightness and whiteness, friction test, contact angle, and antibacterial activity. The nanomaterial at a percentage of $12 \%$ showed the best results when it was added to the paint. These results include adhesion strength, hardness strength, and exposing to weather conditions of temperature, and humidity. The adhesive strength increased when adding the nanomaterial from 112 to 139 before exposure to the weather and from 58 to 108 after exposure. The hardness also increased from 77.9 to 86.5 before exposure to the surrounding environment and from 94.2 to 96.8 after exposure. In addition, the paint with $\mathrm{TiO}_{2}$ nanoparticles exhibited antibacterial activity against two types of bacteria Escherichia coli (E. coli), staphylococcus aurous (S. aurous) and antifungal candida. Paint with $\mathrm{TiO}_{2}$ nanoparticles is more efficient as antibacterial agents with E. coli as compared with $S$. aurous and candida.
\end{abstract}

\section{Introduction}

Titanium dioxide $\left(\mathrm{TiO}_{2}\right)$ has numerous applications that are friendly to the environment, such as: paint, sunscreen, and food colouring. $\mathrm{TiO}_{2}$ under UV illumination displays photograph synergist movement that empowers the oxidative obliteration of a wide scope of natural mixtures and organic species, causing self-cleaning impact. In extra, $\mathrm{TiO}_{2}$ uncovered under UV displays photograph chemically prompted super hydrophilicity that changes the hydrophobic character of the surface over to hydrophilic and structures the uniform water film, which forestalls the attachment of inorganic or natural parts on its surface, tidiness[1]. This is credited to its electronic and optical 
properties, minimal effort, non-poisonousness, high solidness, and high proficiency in the debasement of natural toxins in air and water. $\mathrm{TiO}_{2}$ exhibits wide band gap $(3.0 \mathrm{eV}$ for rutile and $3.2 \mathrm{eV}$ for anatase) which restricts its light absorption to the only ultraviolet region. Consequently, pure $\mathrm{TiO}_{2}$ works as a photo-catalytic material under UV light (4-5\% of solar light), but it has a very weak photo-catalytic activity in visible light (45\% of solar spectrum). This restricts the applications of $\mathrm{TiO}_{2}$ as a photo-catalyst and in the solar light collecting [2] [3]. Transparent $\mathrm{SiO}_{2}-\mathrm{TiO}_{2}$ films on glass could form the basis for self-cleaning of indoor windows, lamps or windshields. To maximize the utilization of titanium dioxide for practical industrial applications, it is necessary to develop $\mathrm{TiO}_{2}$ film type, especially for photo-catalytic applications. Titanium dioxide forms three diverse translucent polymorphic structures: rutile (tetragonal), anatase (tetragonal) and brookite (orthorhombic). Among these, the anatase stage as a rule shows the best photograph synergist conduct, while the rutile stage is the steadiest stage. Photograph impetuses might be utilized as a suspension in a watery arrangement or it could be immobilized on to a supporting substrate [4]. Self-cleaning surface is conceivably a valuable expansion for some business items because of financial, stylish, and natural reasons. Self-cleaning materials that can be cleaned by just being flushed with water can be conceivably applied in numerous spaces [5]. Finally, the preparation of nanoscale materials in the manner of sol-gel and study conduct the application tests, its impact on the environment in terms of disposal of dust and various environmental pollutants using several measurements or tests including measurement of the angle of contact, antibacterial (gram-positive and negative), mechanical test when adding to the local paint etc.

\section{Experimental Procedure}

Sol-gel technique is a wet synthetic cycle that permits a metal oxide to be delivered from naturally altered precursor materials at lower handling temperatures than a customarily made inorganic oxides [6]. The sol-gel method depends on inorganic polymerization responses. It incorporates four stages: hydrolysis, polycondensation, drying and warming disintegration. Hydrolysis of the antecedents of the metal or non-metal alkoxides takes place with water or alcohols [7].

$$
\mathrm{Ti}(\mathrm{OR})_{4}+4 \mathrm{H}_{2} \mathrm{O} \longrightarrow \mathrm{Ti}(\mathrm{OH})_{4}+4 \mathrm{ROH} \ldots \text { (hydrolysis) }
$$

where $\mathrm{R}$ = alkyl bunch. In addition to water and alcohol, an acid or a base also helps in the hydrolysis of the precursor. After condensation of the solution to a gel, the solvent is removed [7].

$$
\mathrm{Ti}(\mathrm{OH})_{4} \longrightarrow \mathrm{TiO}_{2}+2 \mathrm{H}_{2} \mathrm{O} \text { (condensation) }
$$

The weight ratio of chemical materials to prepare the local paint is shown in Table (1).

Table (1). The Weight ratio of chemical materials used in dye [8].

\begin{tabular}{|c|c|}
\hline Material & Weight ratio (\%) \\
\hline Alkyd resin & 55 \\
\hline Titanium dioxide & 12 \\
\hline Calcium carbonate & 12.5 \\
\hline Thickener material & 3 \\
\hline Dilute material & 14.6 \\
\hline Cobalt dryer & 0.6 \\
\hline Lead dryer & 0.4 \\
\hline Calcium dryer & 1.2 \\
\hline Dilute grinding & 0.5 \\
\hline assistant & 0.2 \\
\hline Anti-flake & \\
\hline
\end{tabular}




\section{Preparation of Nano $\mathrm{TiO}_{2}$ Solution}

A $1 \mathrm{ml}$ of concentrated hydrochloric acid was added to $15 \mathrm{ml}$ of titanium trichloride $\left(\mathrm{TiCl}_{3}\right) .250 \mathrm{ml}$ of distilled water then gradually added to the previous solution followed by adding $150 \mathrm{ml}$ of ethyl alcohol. The formed solution was then stirred continuously at $70^{\circ} \mathrm{C}$ for 5 hours. Afterward, $60 \mathrm{ml}$ of ammonium hydroxide solution added while stirring is continued. The resulted solution was left for 24 hours to complete the reaction quietly.

\section{Preparation of Local Paint}

The alkyd resin is weighed, then added the dilute grinding assistant and mixed well. The pigment is added to the alkyd resin, so it will be nano- or microparticles. Calcium carbonate and thickener are added respectively, to the mixture and mixed well after each addition. The mixture was left one day to moisturize the solids well with alkyd resin. On the second day, the solvents, dryers, and anti-flakes are added to the mixture and mixed them well after each addition. $\mathrm{The}^{\mathrm{TiO}_{2}}$ mixture with a percentage of $12 \%$ was added to the dye and mixed well until it became homogeneous by the magnetic mixer. And then the composite materials were mixed with a local paint, and poured on the plates made of iron with dimensions of $10 \mathrm{~cm} \times 5 \mathrm{~cm}$ and left for a whole day till the dye dried up. Several assays were made including the hardness, paste, and color degree examination such as whiteness, brightness, and exposure to weather conditions (heat and moisture) to accelerate weather conditions impacts.

\section{Results and Discussion}

\section{Surface Topography}

Figure (1) shows the atomic force microscope (AFM) test of the nanometres titanium oxide powder obtained by the (sol-gel) process thin fime prepared from $\mathrm{TiO}_{2}$ by spraying the material on a glass base, with a thickness of 56 $\mathrm{nm}$, an area of $(1000 \times 1000) \mathrm{nm}$ square, and the average roughness is about $6.76 \mathrm{~nm}$. The record was previously taken from the published research [9].

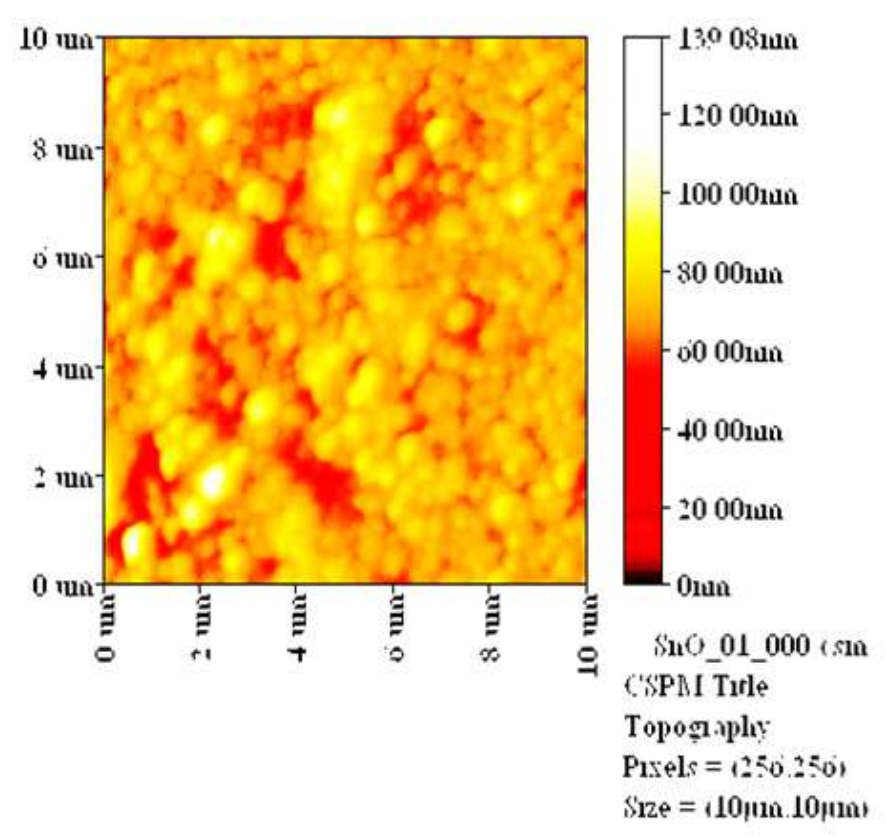

CSPM Imager Surface Roughness Analysis

Image size: $10000.00 \mathrm{~nm} \times 10000.00 \mathrm{~nm}$

Amplitude parameters:

Sa(Roughness Average) $5.54[\mathrm{~nm}]$

Sq(Root Mean Square) 7.48 [nm]

Ssk(Surface Skewness) 0.61

Sku(Surface Kurtosis) 5.17

Sy(Peak-Peak) 74.3 [nm]

$\mathrm{Sz}$ (Ten Point Height) 65 [nm]

Figure (1). AFM examination of the thin film $\mathrm{TiO}_{2}$.

\section{Adhesion Pull-Off}

The bond strength of nano $\mathrm{TiO}_{2}$ paint is significantly higher than micro $\mathrm{TiO}_{2}$ paint for both cases; before exposure to weather conditions and after exposure to weather conditions (ultraviolet, visible, and moisture). The quality of interface and the strength of the adhesion at the interface determine the load transfer between the matrix and the nano fillers [10]. Table (3) shows that $\mathrm{TiO}_{2}$ nanoparticles content can improve adhesion. This positive result can be attributed to the reinforcement provided by the good dispersion and high compatibility between the paint and the nano $\mathrm{TiO}_{2}$. The importance of adhesion is the ability of a coating to resist removal from the surface to which 
it is applied [11]. Such adhesion can be between substrate and coating or between a primer coating and a top coating.

Table (3). Adhesion strength of the paint before and after exposure to weather conditions.

\begin{tabular}{|c|c|}
\hline $\begin{array}{c}\text { Adhesion before exposure to } \\
\text { weather conditions (MPa) }\end{array}$ & $\begin{array}{c}\text { Adhesion after exposure to } \\
\text { weather conditions (MPa) }\end{array}$ \\
\hline Paint with micro $\mathrm{TiO}_{2}=112$ & Paint with micro $\mathrm{TiO}_{2}=58$ \\
\hline Paint with nanoTiO & $=139$ \\
\hline
\end{tabular}

\section{Hardness Test (Shore B)}

Coating hardness is the ability to resist permanent indentation, scratching, cutting, and penetration by a hard object [11]. Different methods of evaluating hardness yield different results, because they measure different qualities of the material. Figure (2) shows the improvement in hardness of the paint with nano $\mathrm{TiO}_{2}$. Hardness results show an excellent interaction between $\mathrm{TiO}_{2}$ nanoparticles and the paint matrix. Moreover, the good dispersion of the particles, leads to an increase in the surface area of the filler. Mechanical properties of the nano composites can be altered by various factor: properties of the matrix, filler particles size and morphology, particles loading and distribution, interfacial adhesion between filler particles and matrix [12]. Figure (3) shows that hardness values increase for both paints (nano and micro) after exposure to weather conditions.

\section{Before exposure to weather conditions}

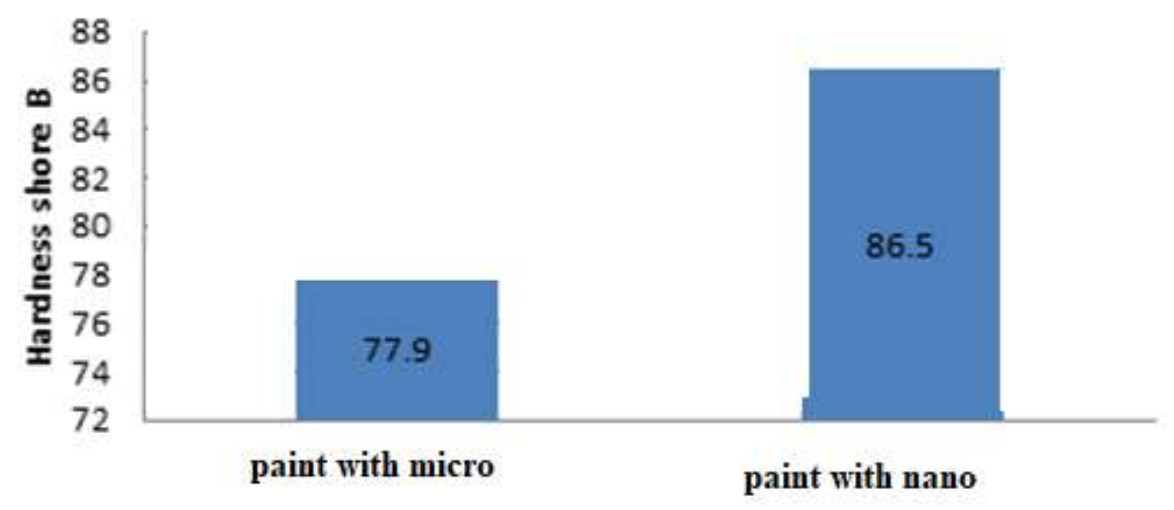

Figure (2). A histogram of Shore hardness for micro and nano $\mathrm{TiO}_{2}$ paints before exposure to weather.

\section{After exposure to weather conditions}

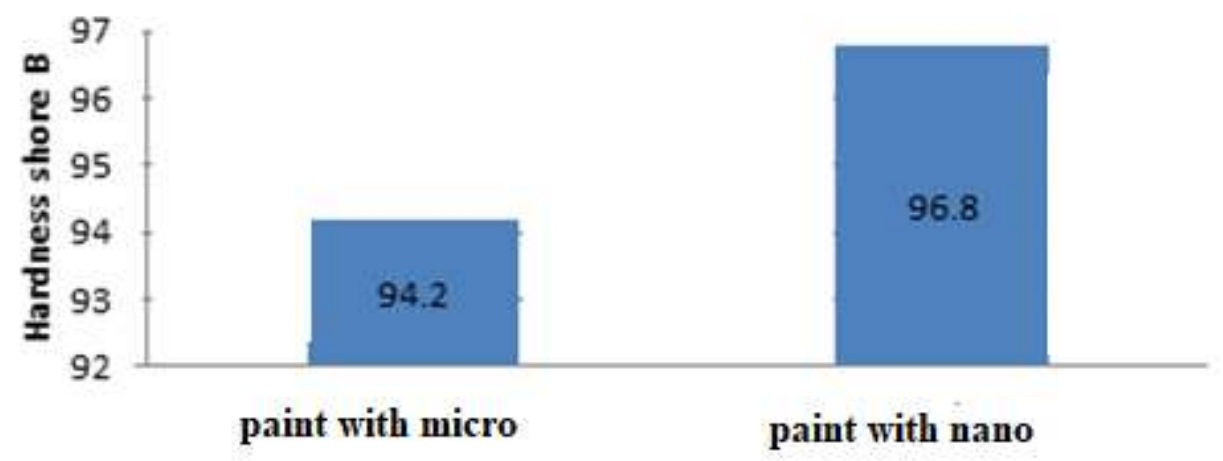

Figure (3). A histogram of Shore hardness for micro and nano $\mathrm{TiO}_{2}$ paints after exposure to weather. 


\section{Friction Test}

The samples of micro paint failed before and after exposure to weather conditions and after the 48 cycles. While the nano paint sample succeeded after exposure to weather conditions. Although, this sample was failed before exposure to weather conditions after 48 cycles.

\section{Brightness and Whiteness}

The brightness of the micro paint was faded after exposure to the weather conditions, whereas the nano paint exhibited a sharper brightness after weather conditions exposure as shown in Table (4). $\mathrm{TiO}_{2}$ is the most widely used white pigment because of its brightness and very high refractive index [13]. Table (5) tabulates the brightness results, where one can see that micro pained samples exhibit a decrease in whiteness after weather exposure compared to its value before the exposure. On the other hand, nano pained samples demonstrate an increase in whiteness after weather exposure.

Table (4). Brightness of paint with micro and nano $\mathrm{TiO}_{2}$.

\begin{tabular}{|c|c|c|}
\hline Samples & $\begin{array}{c}\text { Before exposure to } \\
\text { weather conditions }\end{array}$ & $\begin{array}{c}\text { After exposure to } \\
\text { weather conditions }\end{array}$ \\
\hline Paint with micro & 175.96 & 169.56 \\
\hline Paint with nano & 165.86 & 176.38 \\
\hline
\end{tabular}

Table (5). Whiteness of paint with micro and nano $\mathrm{TiO}_{2}$

\begin{tabular}{|c|c|c|}
\hline Samples & $\begin{array}{c}\text { Before exposure to } \\
\text { weather conditions }\end{array}$ & $\begin{array}{c}\text { After exposure to } \\
\text { weather conditions }\end{array}$ \\
\hline Paint with micro & 141.32 & 128.03 \\
\hline Paint with nano & 130.76 & 139.38 \\
\hline
\end{tabular}

\section{Contact Angle}

Contact angle measurement is shown in Figure (4). When the contact angle increases to more than $90^{\circ}$, the surface is considered a hydrophobic, but when the surface contact angle is less than $90^{\circ}$, the surface is hydrophilic. In the present work, with ultraviolet radiation, sun, moisture and $\mathrm{TiO}_{2}$ nanoparticles, the surface contact angle converts from hydrophilic to super hydrophilic for $\mathrm{TiO}_{2}$ nano and micro paints. Exposure to weather conditions results in a decrease in contact angle for both micro paint and nano paint surfaces which creates a hydrophilic surface. Hydrophlilcity depends on both the surface roughness and the chemical composition [14]. 


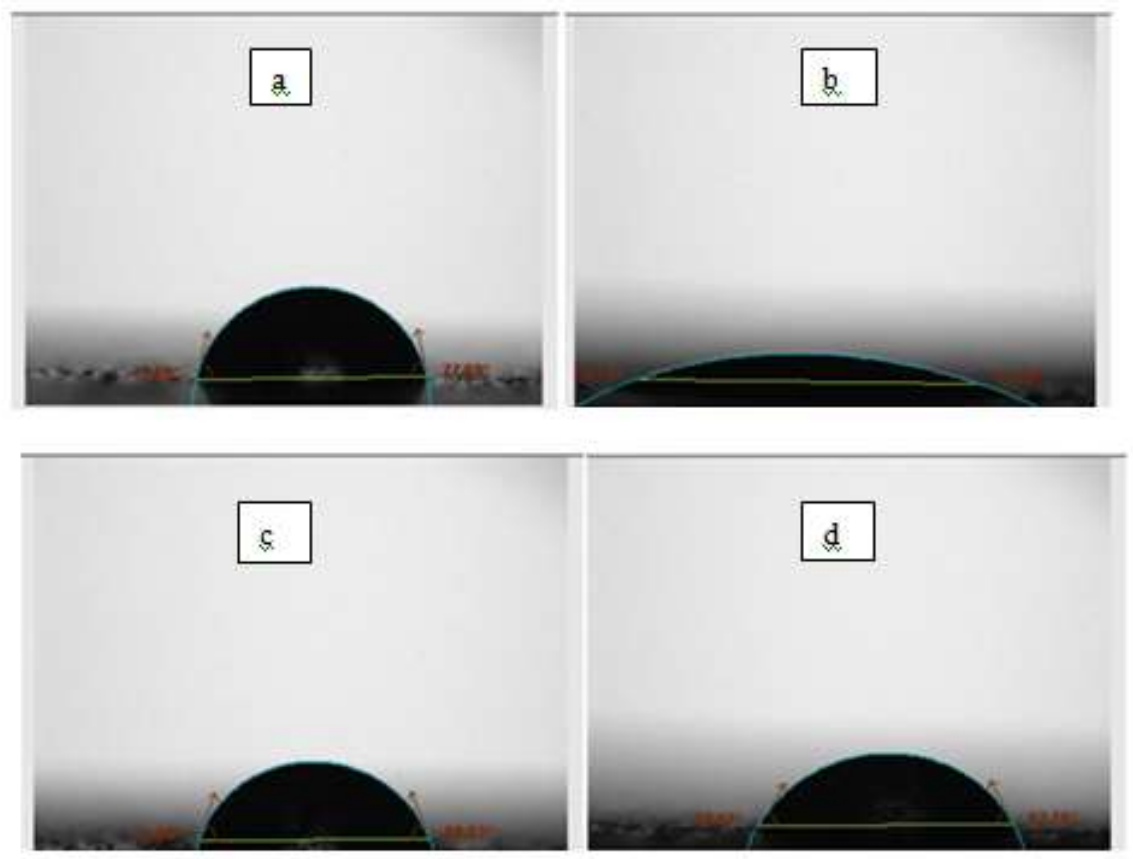

Figure (4). Contact angle: (a) paint with micro $\mathrm{TiO}_{2}$ before exposure to weather condition (b), paint with micro $\mathrm{TiO}_{2}$ after exposure to weather condition, (c) paint with nano $\mathrm{TiO}_{2}$ before exposure to weather condition, and (d) paint with nano $\mathrm{TiO}_{2}$ after exposure to weather condition.

The paint with $\mathrm{TiO}_{2}$ nanoparticles was investigated as antibacterial in two different bacteria: Escherichia coli (E. coli), Staphylococcus aureous (S. aureus), and fungal Candida, as well. Paint with $\mathrm{TiO}_{2}$ nanoparticles showed greater antibacterial activity. The exact mechanisms of the antibacterial action have not yet been clearly identified. $\mathrm{TiO}_{2}$ nanoparticles have bactericidal effects on both Gram-positive ( $S$. aureus) and Gram-negative (E. coli) bacteria. The antibacterial activity of $\mathrm{TiO}_{2}$ nanoparticles depends on the surface area and concentration, while the crystalline structure and particle shape have little effect. Zone of inhibition values determined nanocomposites is shown in Table (6) and Figure (5). $\mathrm{TiO}_{2}$ nanoparticles pronounced significant growth inhibitory effect against both bacteria due to their large surface area by their nanosize. However, $\mathrm{TiO}_{2}$ nanoparticles superior antibacterial activity against $E$. coli bacteria than with $S$. aureus bacteria which are clearly visualized in the antibacterial photographs [15].

Table (6). Zone of inhibition (mm) of paint with $\mathrm{TiO}_{2}$ Nano particle.

\begin{tabular}{|c|c|c|c|}
\hline Samples & S. aureus & E. coli & Candida \\
\hline Area 1 & 17 & 18 & 14 \\
\hline Area 2 & 17 & 18 & 14 \\
\hline Area 3 & 17 & 18 & 14 \\
\hline
\end{tabular}




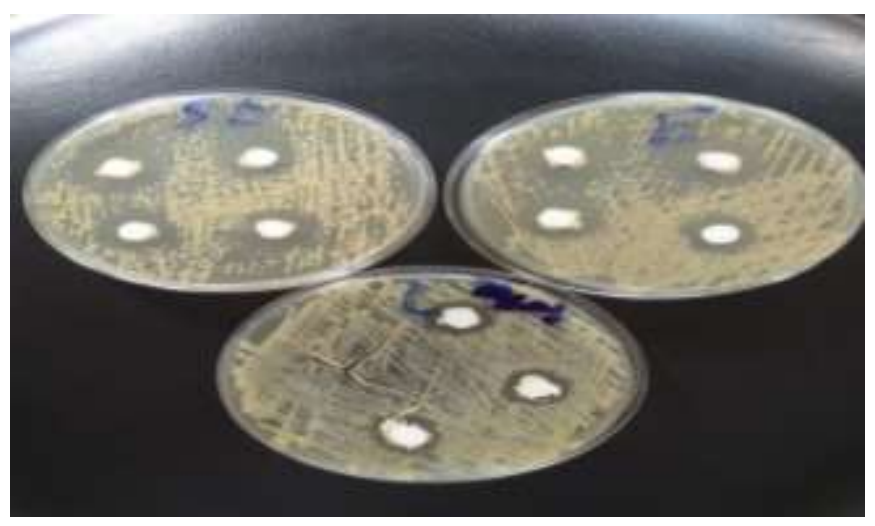

Figure (5). Antibacterial and antifungal activity of Nano paint.

\section{Conclusions}

The $\mathrm{TiO}_{2}$ nanoparticles prepared by chemical method (sol-gel) gave good results. When adding it to the local dye when conducting several dye tests, including adhesive and hardness and contact angle. Examined the dye before it was exposed to weather conditions and after exposure in a micro-form once and in a nano, in the other, the adhesion strength and hardness increased with adding the nanomaterial.

\section{References}

[1] W. Sangchay, "The Self-cleaning and Photocatalytic Properties of $\mathrm{TiO}_{2}$ Doped with $\mathrm{SnO} 2$ Thin Films Preparation by Sol-gel Method," Energy Procedia, vol. 89, pp. 170-176, 2016.

[2] S. M. Reda, M. Khairy, and M. A. Mousa, "Photocatalytic activity of nitrogen and copper doped $\mathrm{TiO}_{2}$ nanoparticles prepared by microwave-assisted sol-gel process," Arab. J. Chem., vol. 13, no. 1, pp. 86-95, 2020.

[3] S. Lourduraj and R. V. Williams, "Effect of molarity on sol-gel routed nano $\mathrm{TiO}_{2}$ thin films," J. Adv. Dielectr., vol. 7, no. 6, pp. 1-7, 2017.

[4] A. Shokuhfar, M. Alzamani, E. Eghdam, M. Karimi, and S. Mastali, " $\mathrm{SiO}_{2}-\mathrm{TiO}_{2}$ Nanostructure Films on Windshields Prepared by Sol-Gel Dip-Coating Technique for Self-Cleaning and Photocatalytic Applications," Nanosci. Nanotechnol., vol. 2, no. 1, pp. 16-21, 2012.

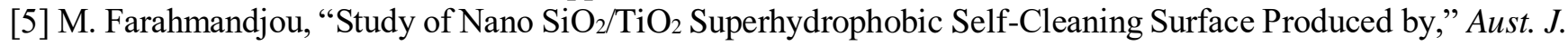
Basic Appl. Sci., no. April 2013, pp. 4-8, 2014.

[6] S. Ibrahem, "Synthesis and characterization of the PMMA / $\mathrm{SiO}_{2}$ hybrids by sol-gel method," Chem. Mater. Res., vol. 6, no. 1, pp. 52-61, 2014.

[7] S. Gupta and M. Tripathi, "A review on the synthesis of $\mathrm{TiO}_{2}$ nanoparticles by solution route," Open Chem., vol. 10, no. 2, pp. 279-294, 2012.

[8] A. A. Salih, A. J. Haider, and A. Nazar, "Preparation and Characterizations of Nanomaterial by Pulsed Laser Ablation in Liquid (PLAIL) as Friendly Environment Paint," J. Phys. Conf. Ser., vol. 1795, no. 1, pp. 0-11, 2021.

[9] Q. A. Kadhum, I. Development, and K. Sahan, "Preparation of Nano-Titanium Dioxide and Manufacturing Nano Thin Film," J. Iraqi Ind. Res., vol. 1, no. 1, pp. 25-31, 2014.

[10] N. Ameer and S. Ibreheim Hussein, "Enhanced thermal expansion, mechanical properties, and adhesion analysis of epoxy / $\mathrm{ZrO}_{2}$ nano composites," J. Phys. Conf. Ser., vol. 1279, no. 1, 2019.

[11] "Paint and Coating Testing Manual, (Gradner-Sward Handbook, 14th Edition) edited by Dr. Joseph V. Koleske, American Society of Testing and Materials, Philadelphia, PA, 1995, pp. 950; hardcover, \$220 list; \$198 ASTM members," Color Res. Appl., vol. 20, no. 4, p. 270, Aug. 1995.

[12] H. Song, J. Liu, F. Xue, and F. Cheng, "Study of inorganic powders used for preparation of waterproof coating to coal mine roadways," Polimery, vol. 61, pp. 844-849, 2016.

[13] R. Sharafudeen, "The manufacturing process parameters affecting color and brightness of $\mathrm{TiO}_{2}$ pigment," Int. J. Ind. Chem., vol. 3, no. 1, pp. 1-7, 2012.

[14] E. Pakdel, W. A. Daoud, and X. Wang, "Self-cleaning and superhydrophilic wool by $\mathrm{TiO}_{2} / \mathrm{SiO}_{2}$ nanocomposite," Appl. Surf. Sci., vol. 275, pp. 397-402, 2013.

[15] A. J. Haider, Z. N. Jameel, and I. H. M. Al-Hussaini, "Review on: Titanium Dioxide Applications," Energy Procedia, vol. 157, pp. 17-29, 2019. 